\title{
SCIDoC
}

International Journal of Dentistry and Oral Science (IJDOS)

ISSN: 2377-8075

\section{Anticariogenic Activity Of Silver Nanoparticles Synthesized Using Fresh Leaves Extract Of Kalanchoe Pinnata}

Research Article

\author{
S Rajeshkumar*, T Lakshmi*
}

Nanobiomedicine Lab, Department of Pharmacology, Saveetha Dental College and Hospitals, Saveetha Institute of Medical and Technical Sciences, Chennai - 600 077, TN, India.

\section{Abstract}

The silver nanoparticles synthesized using herbal plants are widely used much biomedical research area. The plant Kalanchoe pinnata is herbal plant with very good nephroprotective activity and called as miracle plant. In this present investigation we have synthesized silver nanoparticles using fresh plant extract of Kalanchoe pinnata leaves. The synthesized particles were characterized using atomic force microscopy for morphological characters and UV-vis spectroscopy for surface plasmon resonance. The Anticariogenic activity of Kalanchoe pinnata mediated silver nanoparticles were tested against Streptococcus mutans, Staphylococcus aureus, Enterococcus faecalis and Candida albicans. The peak at $420 \mathrm{~nm}$ confirms the silver nanoparticles and zone of inhibition in the microbial plates demonstrate the Anticariogenic activity.

Keywords: Silver Nanoparticles; Kalanchoe Pinnata; Green Synthesis; Anticariogenic Activity.

\section{Introduction}

The nanotechnology is the advanced field with applications in various biomedical applications. The nanoparticles are the major element in the nanotechnology and its various research developments [1-4].

Chemical and physical synthesis techniques lead to the presence of some dangerous synthetic species adsorbed on the surface that may have troublesome impacts in clinical applications $[5,6]$. In chemical intervened synthesis of nanoparticles, some poisonous substances could be utilized as reducing and stabilizing agent to end the agglomeration. Therefore, researchers in the field of the nanoparticle synthesis have gone to green synthesis method $[7,8]$.

Metallic nanoparticles have been broadly misused for biomedical application and among them, silver nanoparticles (AgNPs) are profoundly striking. Their natural highlights, for example, optical, electronic, physicochemical and, surface plasmon resonance (SPR); which can be modified by changing the characteristic features of particles, for example, shape, size, aspect ratio, or condition; easy synthesis and functionalization properties have come about to different applications in various fields of biomedicine, for example, detecting, drug delivery, imaging, photothermal and photodynamic theraphy [9-12].

In the present investigation, we have synthesizedsilver nanoparticles using Kalanchoe pinnata plant extract.

\section{Materials And Methods}

The chemicals used in this study such as Silver nitrate, Mueller Hinton agar were purchased from Hi-media laboratories Pvt. Ltd, India.

\section{Biosynthesis of silver nanoparticles using Kalanchoe pin- nata Plant extract}

Fresh leaves of Kalanchoe pinnatawere collected from garden in Chennai. The Kalanchoe pinnataleaves were washed thoroughly and removed all the contaminants present on the leaves' skin with soap water followed by deionised water. The washed leaves were crushed finely and mixed in $100 \mathrm{~mL}$ of distilled water and heated at $80^{\circ} \mathrm{C}$ for about 10 minutes using a heating mantle. The extract

\section{*Corresponding Author:}

Dr. T Lakshmi and Dr. S Rajeshkumar,

Nanobiomedicine Lab, Department of Pharmacology, Saveetha Dental College and Hospitals, Saveetha Institute of Medical and Technical Sciences, Chennai - 600 077, TN, India. Tel: 9841504523

E-mail: lakshmi@saveetha.com, ssrajeshkumar@hotmail.com

Received: May 28, 2021

Accepted: June 16, 2021

Published: July 02, 202

Citation: S Rajeshkumar, T Lakshmi. Anticariogenic Activity Of Silver Nanoparticles Synthesized Using Fresh Leaves Extract Of Kalanchoe Pinnata. Int J Dentistry Oral Sci. 2021;8(7):2985- 2987. doi: http://dx.doi.org/10.19070/2377-8075-21000607

Copyright: S Rajeshkumar, T Lakshmi ${ }^{\circ}$ 2021. This is an open-access article distributed under the terms of the Creative Commons Attribution License, which permits unrestricted use, distribution and reproduction in any medium, provided the original author and source are credited. 
were filtered using No 1 Whattman filter paper and used to synthesize silver nanoparticles, $10 \mathrm{~mL}$ of Kalanchoe pinnata extract was added into $90 \mathrm{~mL}$ of $1 \mathrm{mM}$ aqueous silver nitrate solution. The reaction mixture was kept in magnetic stirrer for 72 hours. The synthesized nanoparticles were characterized using UV-vis spectrophotometer and atomic force microscope [13].

\section{Anticariogenic activity}

The Anticariogenic activity of silver nanoparticle was determined against oral pathogens like Streptococcus mutans, staphylococcus aureus, Enterococcus faecalis and candida albicans.

The agar well diffusion method was used to check the Anticariogenic activity of silver nanoparticlesandamoxiriteas standard, In the $100 \mathrm{~mL}$ of Muller Hinton agar and $20 \mathrm{~mL}$ of rose Bengal agar was prepared and sterilized. Sterilized medium was then poured into 4 petri plates of $180 \mathrm{~mm}$ diameter and it was allowed to solidify. Using sterile swab, the prepared bacterial suspension was streaked onto the surface of medium. Four $6 \mathrm{~mm}$ diameter wells were then punched using sterile cork borer. The three different concentration of nanoparticles were loaded in the wells. The plates were then incubated at $37^{\circ} \mathrm{C}$ for 24 hours. After incubation, the plates were observed for zone of inhibition and the diameter of zone of inhibition was measured in $\mathrm{mm}$ [14].

\section{Results and Discussion}

\section{Visual observation}

The colour change during nanoparticle synthesis confirms the reducing and stabilizing ability of plant extract [15]. The figure 1 shows the, formation of light yellow to dark brown colour in the reaction mixture could confirm the presence of formation of silver nanoparticles which also denotes the ability of the Kalanchoe pinnata plant extract to reduce silver nitrate into silver nanoparticles.

\section{UV- Visible Spectroscopy}

The UV-Visible spectroscopy was used to characterize the Kalanchoe pinnata mediated silver nanoparticles to find structural properties of silver nanoparticles. The absorbance spectra range from 345 to $445 \mathrm{~nm}$ and the reaction time (12h and $24 \mathrm{~h}$ ) of silver nanoparticles as shown in fig 2 . The absorption peak of Kalanchoe pinnata intervened silver nanoparticles was obtained at 425 $\mathrm{nm}$ which denotes the intense absorption in visible light region. It was states the reduction and stabilization capability of Kalanchoe pinnata extract. The UV results of previous studies such as seems to be concurrent with this study [16-18].

Figure 1. Visual observation for silver nanopartilces synthesis.
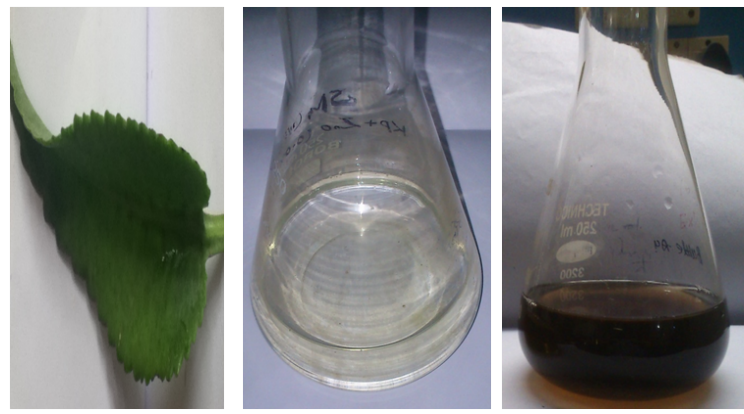

Figure 2. UV-Visible spectra image of Kalanchoe pinnata mediated silver nanoparticles.

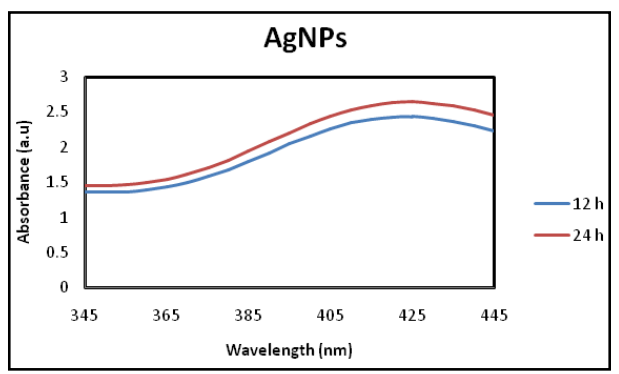

Figure 3. AFM image of Kalanchoe pinnata mediated silver nanoparticles.
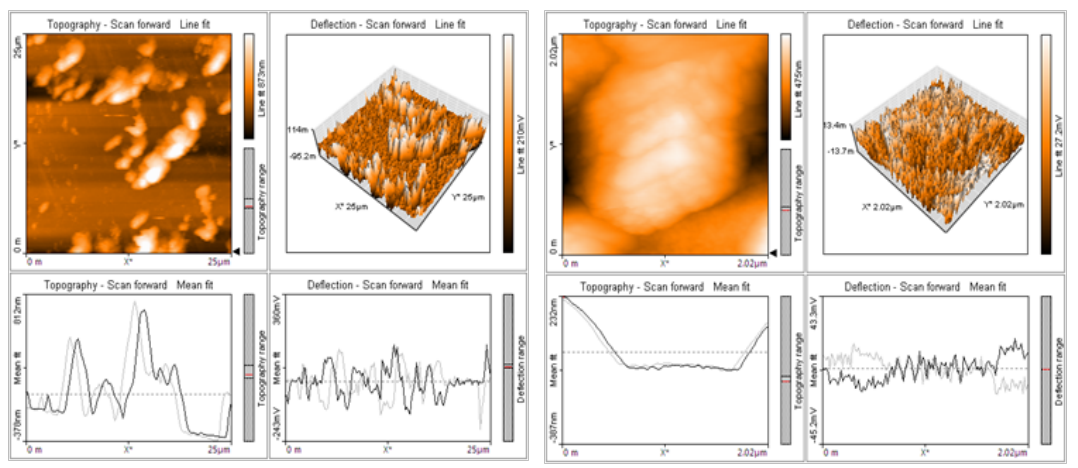
Figure 4. Anticariogenicactivity of silver nanoparticles.

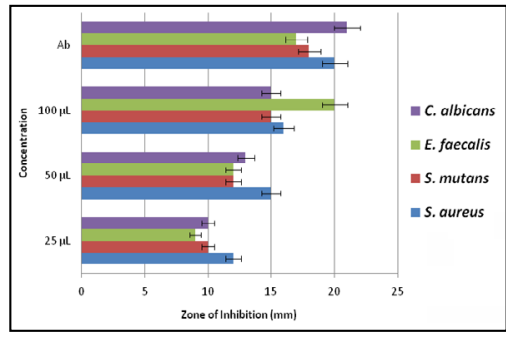

\section{Atomic Force Microscopy}

Atomic force microscopy was used to characterize the Kalanchoe pinnatamediated silver nanoparticles in three dimensional form with sub-nanometer resolution. And the corresponding AFM image was shown in Fig 3. The AFM imaging was conducted in $2.02 \mu \mathrm{m}$ and $475 \mathrm{~nm}$. The size of the silver nanoparticles as predicted by AFM analysis seems to be in agreement with the SEM results. The obtained AFM results found to be concurrent with the existing works [19].

\section{Anticariogenic Activity}

The figure 4 clearly shows the Anticariogenic activity of silver nanoparticles against Streptococcus mutans, staphylococcus aureus, Enterococcus faecalis and candida albicans. In that, the fungus Candida albicans shows maximum zone of inhibition. The Satphylococcusaureusshows the very god zone of inhibition in bacterial strain. The remaining bacterias like Streptococcus mutans and Enterococcus faecalis shows the moderate zone of inhibition by the plant mediated silver nanoparticles. The silver nanoparticles synthesized using different plant extracts are having killing property against different oral pathogens [20-23].

\section{Conclusion}

In dentistry, oral pathogens are major reason for many oral health complications. The development of advanced medicine to control oral pathogens is very important now a day. In this study we synthesized the silver nanoparticles using herbal plant Kalanchoe pinnata fresh plant extract. It shows very good Anticariogenic activity against three bacterial strains and one fungal strain. Based on this positive result we will use the nanoparticles for the preparation of tooth paste and mouthwash in future.

\section{References}

[1]. Rajeshkumar S, Nandhini NT, Manjunath K, Sivaperumal P, Prasad GK, Alotaibi SS, et al. Environment friendly synthesis copper oxide nanoparticles and its antioxidant, antibacterial activities using Seaweed (Sargassum longifolium) extract. J. Mol. Struct. 2021 May 23:130724.

[2]. Solanki LA, Sundari KKS, Rajeshkumar S. In-vitro Cytotoxicity Evaluation of Green Synthesized Gold Nanoparticles and Its Indigenous Mouthwash. J Pure ApplMicrobiol. 2021;15(2):735-742.

[3]. UB S, RAMESH S, RAJESHKUMAR S. In Vitro Cytotoxic Analysis of Solanum Xanthocarpum induced silver nanoparticles on Brine Shrimp Artemia. Ann. Romanian Soc. Cell Biol. 2021 May 9:3544-52.

[4]. KA MT, Rajeshkumar S, Anjali AK. Anti Inflammatory Activity of Silver Nanoparticles Synthesised Using Indian Herbs-A Review. Ann. Romanian Soc. Cell Biol. 2021 Mar 30:5904-14

[5]. Sivarajan M, Rajeshkumar S, Ezhilarasan D. Role of Silver Nanoparticles in Antioxidant Property. Ann. Romanian Soc. Cell Biol. 2021 Mar 20:693703.
[6]. IffatNasim, S. Rajeshkumar, V Vishnupriya. Green Synthesis Of Reduced Graphene Oxide Nanoparticles, Its Characterization and Antimicrobial Properties against Common Oral Pathogens. Int J Dentistry Oral Sci. 2021;8(2):1520-1525.

[7]. Rajeshkumar S, Sivaperumal P, Tharani M, T Lakshmi. Green Synthesis of Zinc Oxide Nanoparticles by Cardiospermum. J Complement Med Res.2020;11 (5):128-136.

[8]. S. Aravind Kumar, RamachandraPrabhakar, N. Raj Vikram, SP Saravana Dinesh, S Rajeshkumar. Antioxidant Activity of Silymarin/Hydroxyapatite/ Chitosan Nano Composites - An In Vitro Study. Int J Dentistry Oral Sci. 2021;8(1):1402-1404.

[9]. Rajeshkumar S, Agarwal H, Sivaperumal P, Shanmugam VK, Lakshmi T. Antimicrobial, anti-inflammatory and anticancer potential of Microbes mediated zinc oxide nanoparticles. J Complement Med Res. 2020;11(5):41-8.

[10]. Rajeshkumar S, Tharani M, Sivaperumal P, Lakshmi T. Synthesis of Antimicrobial Silver Nanoparticles by Using Flower of Calotropis Gigantea. J Complement Med Res. 2020;11(5):8-16

[11]. Rajeshkumar S, Malarkodi C, Al Farraj DA, Elshikh MS, Roopan SM. Employing sulphated polysaccharide (fucoidan) as medium for gold nanoparticles preparation and its anticancer study against HepG2 cell lines. Mater. Today Commun. 2020 Mar 1;26:101975.

[12]. Selvapriya S, Monika K, \& Rajeshkumar S. Antioxidant activity of silver nanoparticles synthesis using Cinnamomumverum and Phyllanthusemblica formulation. Int. J. Pharm. Sci. Res. 2020; 11(4), 6918-6921.

[13]. Shunmugam R, Balusamy SR, Kumar V, Menon S, Lakshmi T, Perumalsamy $\mathrm{H}$. Biosynthesis of gold nanoparticles using marine microbe (Vibrio alginolyticus) and its anticancer and antioxidant analysis. J KING SAUD UNIV SCI. 2021 Jan 1;33(1):101260.

[14]. Rajeshkumar S, Sherif MH, Malarkodi C, Ponnanikajamideen M, Arasu $\mathrm{MV}$, Al-Dhabi NA, et al. Cytotoxicity behaviour of response surface model optimized gold nanoparticles by utilizing fucoidan extracted from padina tetrastromatica. J. Mol. Struct. 2020 Mar 15;1228:129440.

[15]. Shathviha PC, Ezhilarasan D, Rajeshkumar S, Selvaraj J. $\beta$-sitosterol Mediated Silver Nanoparticles Induce Cytotoxicity in Human Colon Cancer HT29 Cells. Avicenna J Med Biotechnol. 2021 Jan-Mar;13(1):42-46.Pubmed PMID: 33680372.

[16]. V.M.KAYAL, LAKSHMINARAYANAN ARIVARASU, S. RAJESHKUMAR3. Characterisation and Cytotoxic potential of hyaluronic acid mediated silver nanoparticles. Int. j. pharm res.2020; 12 (1) : 2931-2936.

[17]. ANTONY, ANITHA ROY, S RAJESHKUMAR, DR. LAKSHMI THANGAVELU4 .Antioxidant and Antibacterial Activity of Silver Nanoparticles Prepared from Horseradish Oil MONICA. Int. j. pharm res. 2020; 12 (1) : 3028-3033.

[18]. George R, Roy A, Rajeshkumar S, Lakshmi T. Coriander oleoresin assisted synthesis and characterization of silver nanoparticles and its antioxidant activity. Biomedicine. 2020 Nov 9;40(3):309-12.

[19]. Singh M, Kalaivani R, Manikandan S, Sangeetha N, Kumaraguru AK. Facile green synthesis of variable metallic gold nanoparticle using Padina gymnospora, a brown marine macroalga. Appl. Nanosci. 2013 Apr;3(2):145-51.

[20]. AnuIswaryaJaisankar, Rajeshkumar S, \&Ezhilarasan D. Applications Of Silver Nanoparticles In Dentistry. Int. J. Res. Pharm. Sci.2020; 11(SPL3): 1126-1131.

[21]. Neethu Ann Preethy, Ganesh Jeevanandan, Rajeshkumar S, \& Subramanian EMG. Antimicrobial activity of chitosan in combination with silver diamine fluoride against streptococcus mutans - An in-vitro study. Int. J. Res. Pharm. Sci.2020; 11(4): 5960-5964.

[22]. Nasim I, Kumar SR, Vishnupriya V, Jabin Z. Cytotoxicity and anti-microbial analysis of silver and graphene oxide bio nanoparticles. Bioinformation. 2020;16(11):831-6.

[23]. Jackson K. Cytotoxic potentials of silibinin assisted silver nanoparticles on human colorectal HT-29 cancer cells. Bioinformation. 2020 Nov 30; 16(11): 817-827. 